\title{
A review on sludge dewatering indices
}

\author{
Vu Hien Phuong To, Tien Vinh Nguyen, Saravanamuth Vigneswaran* and Huu Hao Ngo
}

Faculty of Engineering and IT, University of Technology, Sydney (UTS), PO Box 123, Broadway, NSW 2007 Australia

* Corresponding author: Tel. +61-2-9514-2641; Fax. +61-2-9514-2633; E-mail:

s.vigneswaran@uts.edu.au

\begin{abstract}
Dewatering of sludge from sewage treatment plants is proving to be a significant challenge due to the large amounts of residual sludges generated annually. In recent years, research and development have focused on improving the dewatering process in order to reduce subsequent costs of sludge management and transport. To achieve this goal, it is necessary to establish reliable indices that reflect the efficiency of sludge dewatering. However, the evaluation of sludge dewaterability is not easy task due to the highly complex nature of sewage sludge and variations in solid-liquid separation methods. Most traditional dewatering indices fail to predict the maximum cake solids content achievable during fullscale dewatering. This paper reviews the difficulties in assessing sludge dewatering performance and the main techniques used to evaluate dewatering performance are compared and discussed in detail. Finally, the paper suggests a new dewatering index, namely "Modified Centrifugal Index (MCI)", which is demonstrated to be an appropriate indicator for estimating the final cake solids content as well as simulating the prototype dewatering process.
\end{abstract}

Key words Dewatering index; dewaterability; filterability; modified centrifugal index; sludge dewatering

\section{Introduction}

Sewage sludge is an inevitable by-product of wastewater treatment. However, in recent decades, the quantities of sludge produced are dramatically increasing due to the rapid growth of industrialization and population as well as more stringent wastewater treatment standards. According to one 2013 survey, Australia's total amount of sewage sludge generated was approximately 1.3 million wet tonnes of biosolids - 200,000 tonnes greater than that in 2010 (Australian Water Association). This results in raised costs of sludge handling and transports, which often constitutes half of treatment costs of wastewater treatment plants. Consequently, various strategies have been made to create the best economic and environmental solutions to this problem.

In sludge management systems, after being pre-treated by thickening, digestion or conditioning, sludge is often dewatered before any further processing occurs such as incineration, composting and landfill (Water Pollution Control Federation 1985). This will result in the reducing sludge volume and, consequently, the cost of transportation (Feng et al. 2009). Despite these efforts, however, sludge dewatering is still a major challenge particularly in designing sludge treatment systems due to the highly complex nature of sewage sludge. Many factors influence dewatering characteristics of sludge (Karr \& Keinath 1978), and this makes it even more complicated and difficult in assessing dewatering performance correctly. Many attempts to identify a proper indicator to truly reflect the efficiency of dewatering 
process have been carried out by establishing relationships between these influencing factors and sludge dewatering properties.

The terms 'filterability' and 'dewaterability' have been used widely to describe the ability to dewater sludge (Sanin et al. 2011) but there is no clear distinction when using these two parameters. Sludge filterability and dewaterability are often cited together and can be interchangeable, which possibly results in confusion and misunderstanding. Bürger et al. (2001) defined filtration as a mechanical method which is commonly applied for solid-liquid separation while Mowla et al. (2013) stated that improving sludge cake filterability is one of several ways to enhance bio-sludge dewaterability. This implies that filterability should have been only used for measuring the of filtration process'sefficiency instead of the whole dewatering effectiveness. Whilst dewaterability indicates the final water content or the maximum solid content achievable for sludge cakes, reducing sludge volume is the ultimate objective of dewatering. Chen et al. (1996) also stated that sludge dewaterability can be characterized by the residue moisture content in the sludge cake and the ease of the filtration process. Yet in many published studies, sludge filterability has been considered as influencing the dewatering process output (Scholz 2005; Yukseler et al. 2007; Sawalha \& Scholz 2010). Traditionally used dewatering indices have been mainly developed for assessing filterability of sludge (Vesilind 2000). This may cause significant errors and inaccuracies in evaluating the efficiency of dewatering. Consequently, besides the simplicity of the filtration process, cake solids concentration should also be considered when assessing dewatering performance. In other words, dewaterability indicators should have the ability to predict maximum cake solids content achievable during full-scale dewatering.

Many studies have suggested that dewatering by filtration equipment consists of two main phases these being filtration and consolidation or expression (Lee \& Wang 2000). Numerous investigators have put efforts on characterizing the two phases to fully describe the full dewatering process. Sørensen et al. (1996) described sludge as a solid-liquid mixture where solids are either in free suspension or packed closely together to form a cake. The former is called filtration phase while the latter is known as expression phase. Novak et al. (1999) stated that the amount of water extracted by filtration alone is not enough to achieve a desired cake solids content; and expression phase accounts for most water removal. For compressible structures, such as biological sludge, the filtration stage can be very short(a few minutes) whereas the consolidation stage can be very long (several hours or even several days) to accomplish (Saveyn et al. 2005).It has been highlighted that the high pressure in dewatering devices has little influence on filtration phase but can help improve the water removal during compression phase (Reichmann \& Tomas 2001).Despite the fact that the importance of expression was recognized many years ago, it has generally been neglected. This could be due to the difficulties of separating the filtration and the expression phases during dewatering. Olivier et al. (2007) proposed an illustration of one dimensional filtration and expression processes to well -describe the difference between the two phases. The filtration rate of sludge is normally described by the Specific Resistance to Filtration (SRF) which utilizes the plot of the inverse flux $(\mathrm{t} / \mathrm{V})$ versus filtrate volume $(\mathrm{V})$ to calculate it (the linear part in the filtrationcompression curve). It could be noticed that once filtration is completed and expression begins, $\mathrm{t} / \mathrm{V}$ will increase dramatically with small volume of filtrate extracted, and, to some extent, this change can be used to differentiate the two phases. Another method to define the two stages was proposed by Konnur et al. (2008). They stated that the expression starts at a point where the particle network can no longer resist elastically. This results in the breakage of interparticle bonds and particle rearrangement, leading to irreversible consolidation. 
Basically, sludge mechanical dewatering can be accomplished by filtration (vacuum filters, filter presses and belt filters) and centrifugation (centrifuges) processes. Sludge dewaterability in these two processes are essentially different (Spinosa \& Mininni 1984). In fact the techniques used to evaluate the sludge dewaterability are specific to each dewatering processes. In this review, various methods for measuring dewatering performance that have been studied and applied over the years are discussed and compared in terms of procedures, advantages and limitations as well as their applications.

\section{Challenges in measuring sludge dewatering performance}

Together with improvements in sludge dewatering to achieve the highest solid content sludge cake, it is essential to establish a reliable dewatering index that can fully express how easily sludge releases its water (Pan et al. 2003). To date, however, there is no universal indicator yet properly reflecting the solid-liquid separation ability of sludge. The main reasons for this problem are linked to different aspects of sludge properties, conditioning and dewatering methods.

Initially, as mentioned earlier, sewage sludge can vary enormously in terms of physical, chemical and biological characteristics, leading to its relatively unpredictable behaviour, especially dewatering behaviour (Colin et al. 1988). This makes it difficult to quantify most of the parameters (Sanin et al. 2011). Although some parameters can be quantified, it has never been easy to correlate these properties with sludge dewatering. Despite this impediment, various typical sludge properties such as $\mathrm{pH}$, particle surface charge, organic content, cake porosity, compressibility, particle size, rheological characteristics, bound water content and solid concentration - variables that can influence dewaterability of sludge - have been investigated by numerous studies. These are summarized in more detail by Karr and Keinath (1978). However, a consensus is still lacking on which ones have the greatest impact on sludge dewatering.

It has been known that conditioning treatment is necessary for most sludge types, especially for bio-sludge which has proven to be naturally difficult to dewater. Of the various conditioning methods, polymer conditioning has been the most popular method and is often employed in mechanical dewatering. However, many investigators have focused mostly on optimizing the conditioning regimes but neglected the effect of dewatering equipment on conditioned sludge (Vaxelaire \& Olivier 2006). Novak et al. (1999) reported that the two fundamental devices used for sludge dewatering, belt filter press and centrifuge, have different conditioning demands. This implies that the selection of conditioning agents is based not only on the nature of the bio-solids but also on the type of mechanical dewatering system.

Most traditional dewaterability measuring techniques, including Capillary Suction Time (CST) and Specific Resistance to Filtration (SRF), often measure the rate of filtration only and overlook the considerable contribution of expression. Therefore, to better understand the limits of dewatering, it is necessary to focus not only on the rate of filtration but also on the rate of expression, which is considered to be most important for achieving drier solid cakes.

The last but not least major problem with most traditional dewatering index procedures is that they barely resemble the actual sludge dewatering processes (Lynch \& Novak 1991), except for SRF measurement, which is quite similar to pressure filters and vacuum filters (Christensen \& Dick 1987; Vaxelaire \& Olivier 2006). It is known that different dewatering devices have different operations and intensity, which greatly affects the efficiency of sludge 
dewatering. Consequently, there should be a method that can estimate the final cake concentration and simulate real dewatering processes. This also suggests that it is not feasible to use only one dewaterability indicator for all dewatering processes. This is because the liquid-solid separation is influenced by numerous parameters, and a single index is hardly sufficient to fully describe the whole process (Vaxelaire \& Cézac 2004). Hence, along with developing accurate measurements of sludge dewatering performance, selecting a proper index for different methods of dewatering is also significantly important (Pan et al. 2003). However, the problem is that it is not easy to simulate the real processes occurring in dewatering equipment. In the present work, besides SRF which can mimic filtration processes, another tool that can be applied to other popularly used dewatering equipment, the centrifuge, is also recommended.

\section{Dewaterability indicators for filtration processes}

\section{Specific Resistance to Filtration (SRF)}

\section{Definition and Procedure}

The SRF test was introduced in 1956 by Coackley and Jones (1956) and it became the very first widely used technique. It is considered as an important parameter for assessing filtration quality of sludge (Lai \& Liu 2004; Qi et al. 2011). The SRF test measures the resistance of sludge to the withdrawal of water through a porous media either by vacuum or pressure (Graham 1999). The higher the specific resistance, the more difficult it is to dewater sludge and vice versa (Karr \& Keinath 1978). In general, sludge with SRF value as low as $10^{10}-10^{11} \mathrm{~m} / \mathrm{kg}$ is classified as easy to dewater; whereas, sludge with SRF value as high as $10^{14}-10^{15} \mathrm{~m} / \mathrm{kg}$ is considered as difficult to extract water. Specific resistance varies with applied pressure, filter area and pore size and liquid viscosity, making it more complicated to measure and compare.

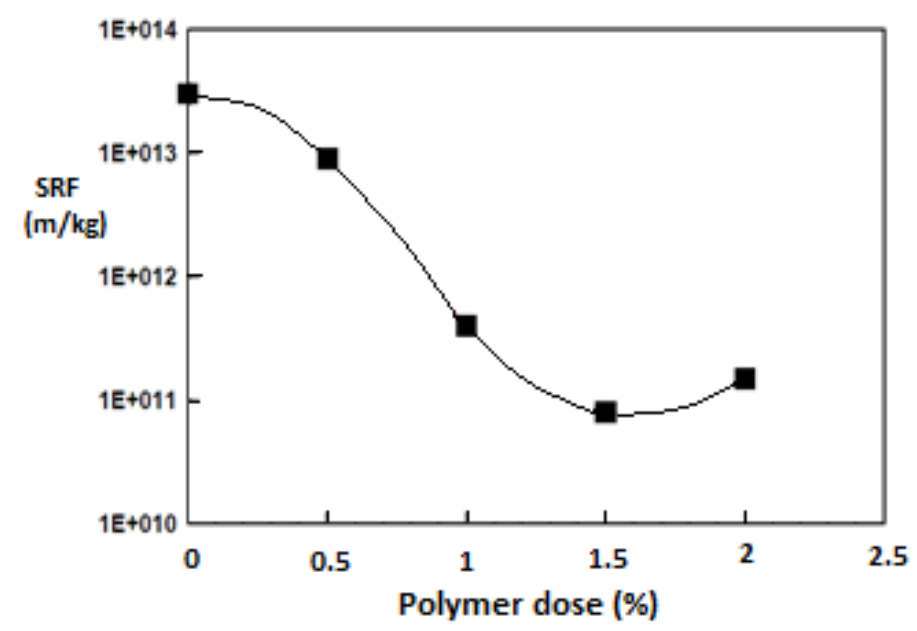

Figure 1 Effect of polymer dose on specific resistance to filtration (figure reprinted from Sanin et al. (2011), (C) DEStech Publications, Inc.)

The SRF parameter has been utilized mainly as a measurement of dewaterability and to optimize sludge conditioning (Figure 1). It is used for various mechanical dewatering devices such as vacuum filters, belt presses and plate and frame presses (Christensen 1983). SRF test was developed as a filtration model for vacuum filtration of sludge. The original measure of SRF uses Buchner funnel apparatus. The instrument set up is shown in Figure 2a. The test is 
conducted by pouring a reasonable volume of sludge into the funnel (with filter paper) and applying the vacuum (measured with a vacuum gauge) at time zero. During the filtration, filtrate volume is recorded as a function of time (Coackley \& Jones 1956). These data are then plotted with inverse flux (time/filtrate volume) versus filtrate volume (Figure $2 b$ ) and the line's slope serves to calculate the specific resistance. Most of investigators determine SRF using the following equation (Christensen \& Dick 1985):

$$
S R F=\frac{2 \Delta P A^{2} b}{\mu \omega}(1)
$$

where $\Delta \mathrm{P}=$ pressure difference(for filtration process, pressure difference refers to liquid pressure), $\mathrm{A}=$ filtration area, $\mathrm{b}=$ the line's slope, $\mu=$ viscosity, $\omega=$ weight of dry cake solids per unit volume of filtrate

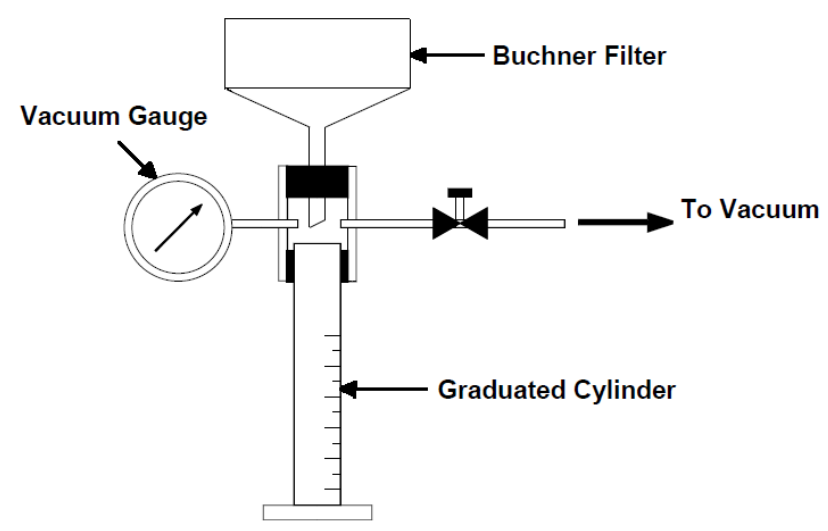

(a)

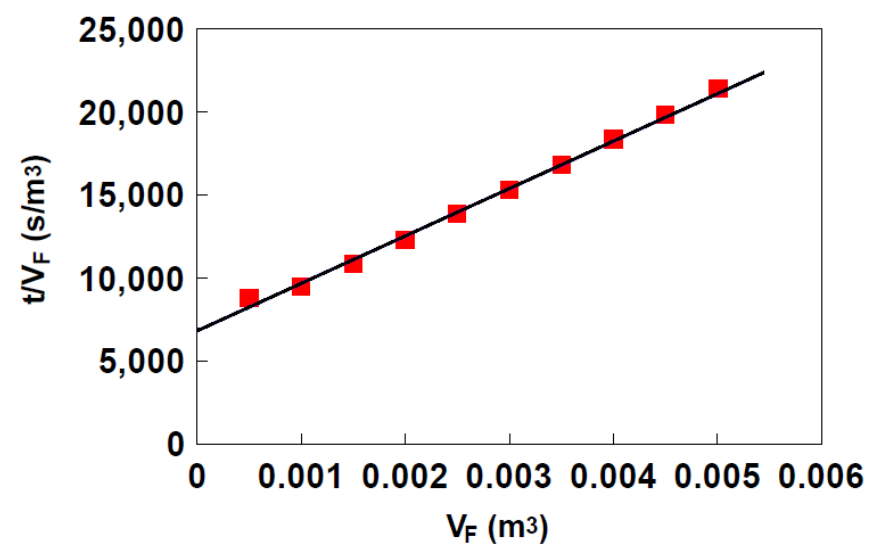

(b)

Figure 2 (a) A Buchner funnel apparatus set - up and (b) plot of the inverse flux versus filtrate volume (figure reprinted from Sanin et al. (2011), () DEStech Publications, Inc.)

As defined earlier, the full dewatering process fundamentally consists of filtration and expression stages. Since SRF is calculated based on the linear part of the filtration-compression curve, it describes only filtration phase. As a result, SRF alone is not sufficient enough to characterize the full process of dewatering (Marinetti et al. 2009).

It has been known that the conventional model of SRF test was genuinely developed for incompressible cakes where filtration is the predominant process and SRF is a constant. Whilst, for compressible cake where compression also plays an important role in dewatering process, 
SRF is proved to be an increasing function of the solid pressure or compressive pressure (Sørensen \& Sørensen 1997).Generally speaking, SRF and solid pressure are two key parameters describing the liquid flow through the cake (filtration phase) and the expression phase, respectively. Developed from the conventional modelling, several models have been proposed to better describe both processes of dewatering, which can be found in a review of Lee and Wang (2000). These proposed models are based on the assumption that the cake permeability decreases (leading to SRF increasing) as the solid pressure increases (Marinetti et al. 2009).

\section{Shortcomings of method}

Although, SRF has been widely accepted as a useful general measurement of sludge dewaterability, certain limitations and confusion have arisen in the determination of SRF (Vesilind 1988). Firstly, the time required for measurements was reached when a cake was formed and eventually cracked with a resultant drop in pressure. However, most sludge contains fibres which prevent the cake from cracking. As a result, investigators in the 1970s measured sludge filterability by examining the time required to obtain a given amount of filtrate from a given initial amount of sludge (Tenney et al. 1970; Notebaert et al. 1975). Moreover, this measurement time also depends on a number of variables such as sample volumes, applied pressure, filter area, pore size and initial solid content of sludge, leading to difficulties in directly comparing results obtained from different studies.

Another problem that compromises the reliability of SRF was the unclear and inconsistent use of the parameter's unit. Gale (1967) reported the units commonly used by early investigators of SRF which were the square seconds per gram $\left(\mathrm{s}^{2} / \mathrm{g}\right)$, centimetres per gram $(\mathrm{cm} / \mathrm{g})$ and meters per kilogram $(\mathrm{m} / \mathrm{kg})$ or tetrameters per kilogram $(\mathrm{Tm} / \mathrm{kg})$. He pointed out that $\mathrm{s}^{2} / \mathrm{g}$ was incorrect and $\mathrm{cm} / \mathrm{g}$ was appropriate. However, Tebbutt (1970) latter suggested that $\mathrm{m} / \mathrm{kg}$ was a better choice for specific resistance in the SI system. Tm/ $\mathrm{kg}$ was subsequently recommended to eliminate the use of cumbersome scientific notation (Christensen 1983).

Most importantly, the testing method for SRF measure has been recognized as a timeconsuming and complicated procedure. It requires much expertise and sophisticated equipment to make it function well, especially for field measurements (Barber et al. 1997; Vesilind 2000).

\section{Capillary Suction Time (CST)}

\section{Definitions and procedures}

The theory of CST was first developed by Baskerville and Gale (1968) as a substitute for SRF test and has been increasingly popular for various applications and disciplines. CST is principally the time required for a certain volume of filtrate drawn out of the sludge and sucked into the blotter paper by capillary force (Vesilind 1988).. Briefly, CST can be deemed as "time to dewater" and the readings are in seconds (Novak 2006). CST has been widely used for assessing the effects of conditioning on sludge filterability as well as determining the optimal dose of conditioners for dewatering processes (Graham 1999). A short CST, which is less than $20 \mathrm{~s}$, is indicative of a readily dewaterable sludge, while a long CST is representative of a poorly dewatering sludge. CST of autothermal thermophilic aerobic digested (ATAD) sludge was found to exceed 50,000s (Agarwal et al. 2005). 
As the first model regarding CST apparatus was devised in 1968 (Baskerville \& Gale 1968), various modifications of the CST test have been implemented in subsequent years. However, the standard CST instrument basically consists of 2 plastic blocks, a stainless steel cylindrical funnel, a Whatman No. 17 filter paper (which is a standard grade of chromatography paper), 3 electrodes fixed in the upper block and connected to an electrical timer (Vesilind 1988). The equipment's installation is shown in Figure 3. The test is carried out by pouring a small amount of sludge into the cylindrical tube. Then under the effect of capillary pressure, filtrate from the sludge flows radially through the filter paper until it reaches the first 2 sensors that activate the timer. The timer stops when the flow reaches the third sensor, giving the value of CST in seconds. The capillary suction pressure is much greater than the hydrostatic pressure inside the funnel and thus the test does not depend on the amount of sludge, as long as there is a sufficient quantity provided to perform the test (Scholz 2005).

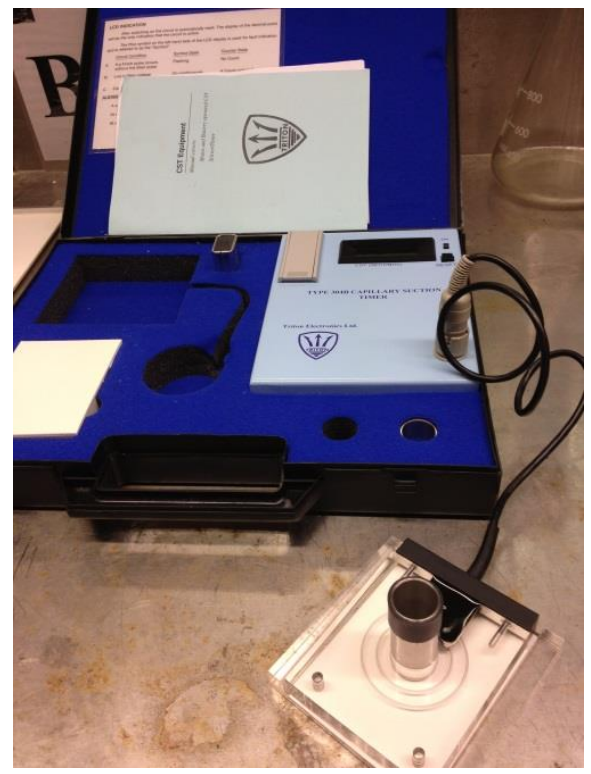

Figure 3 The standard apparatus (Model 304B CST, Triton Electronics Ltd.)

As can be noticed, CST is also a function of various parameters such as filter paper properties, instrumental properties and sludge-related properties (Vesilind 1988) in the following form:

$$
C S T=\emptyset\left[\frac{\mu C}{\chi}\right]
$$

where $\emptyset=$ a dimensionless instrument constant, $\mathrm{C}=$ solid concentration, $\chi=$ filterability constant

\section{Shortcomings of method}

Unlike SRF, CST is affected by the concentration of solids, and therefore it is not meaningful to compare CST of different sludge types from different plants (Vesilind 1988). As a response, a normalized value of CST was proposed and applied for the purpose of comparison. The value is determined by dividing CST value by the initial total suspended solids (TSS) concentration of sludge and expressed in unit of seconds per litre per gram TSS (Yu et al. 2008).

Besides, although the CST method has been effective in characterizing a majority of sludge, it is not often used in determining optimum polymer dose (OPD) for well-flocculated sludge which occurs around OPD point. This is attributed to the too-fast escape of water from the floc (Scholz 2005; Sanin et al. 2011). For this reason, Vesilind (2000) developed a new 
CST measurement using a modified CST apparatus that allows the filterability of superflocculated sludge to be evaluated. Here the procedure is carried out by first draining the free water from the well-conditioned sludge and then leaving only flocculated sludge exposed to the filter paper.

Another emerging problem concerning CST measurement is related to the use of standard filter paper, specifically the Whatman No. 17 chromatographic paper. Although this paper has been used worldwide, some disadvantages were noted including anisotropic properties, relatively over-sized pores and economic concerns. Conversely, less expensive filters such as the Fisher 200 chromatographic papers, SS1107 and SS3205, chromatographic papers can be used without significantly changing the range of expected CST values (Sawalha \& Scholz 2007).

Despite various efforts to improve the CST test's precision and reliability, the method has still encountered many unresolved problems. For instance, it was reported that using CST and SRF tests to determine OPD could lead to over-dosing, especially in the case of polymer conditioning. Christensen et al. (1993) explained that it is because the calculations of both modified CST and SRF used the filtrate viscosity which is directly proportional to the conditioner dose, causing the measures to be inaccuracies. Another major reason for the unreliability of CST results is that since little pressure is a on the sludge floc during measurement, CST cannot truly reflect the floc strength or resistivity to shear during dewatering stage (Pan et al. 2003).

\section{Relationship between CST and SRF}

As mentioned earlier, CST was developed as a substitute for SRF to measure dewatering rate. However, since CST is only an empirical method, it is unable to predict the cake solids content as well as simulate the real dewatering process compared to SRF. Vesilind (1988) discussed that failures in relating CST to SRF were due to the fact that SRF should correlate with filterability constant $(\chi)$ instead of CST. He also stated that SRF and $\chi$ are both fundamental measures of dewaterability.

Despite of that, various studies have tried to investigate and model the relationship between CST and SRF with the purpose of obtaining the averaged specific resistance of filtration cake from the data generated by CST tests. Lee and Hsu (1994) proposed a method that allowed SRF to be calculated without the liquid invasion volume measurement using capillary suction apparatus. A similar work by Herwijn et al. (1995) presented a newly developed model of CST apparatus able to determine specific cake resistances of both unflocculated and flocculated sludges. Sawalha and Scholz (2010) provided a mathematical model which related CST, SRF and other parameters, such as temperature and solids content. These can also predict the results of SRF tests from those of CST tests. Most recently, Peng et al. (2011) obtained a relatively good correlation between normalized CST and SRF $\left(\mathrm{R}^{2}=\right.$ 0.9450). They concluded that it is not necessary to use both these parameters simultaneously to evaluate the dewatering rate.

\section{Methods for measuring the extended phase of dewatering using filtration processes}

Novak et al. (1999) emphasized that the change in cake volume and liquid pressure are more appropriately indicative of expression phase. Figure 4 shows that expression occurs as the cake depth begins to decrease and the liquid pressure is no longer constant. By separating the filtration from the expression, they also recommended an energy-saving solution for 
dewatering equipment, especially for belt press, so that filtration stage could be executed under very low pressure such as gravity.

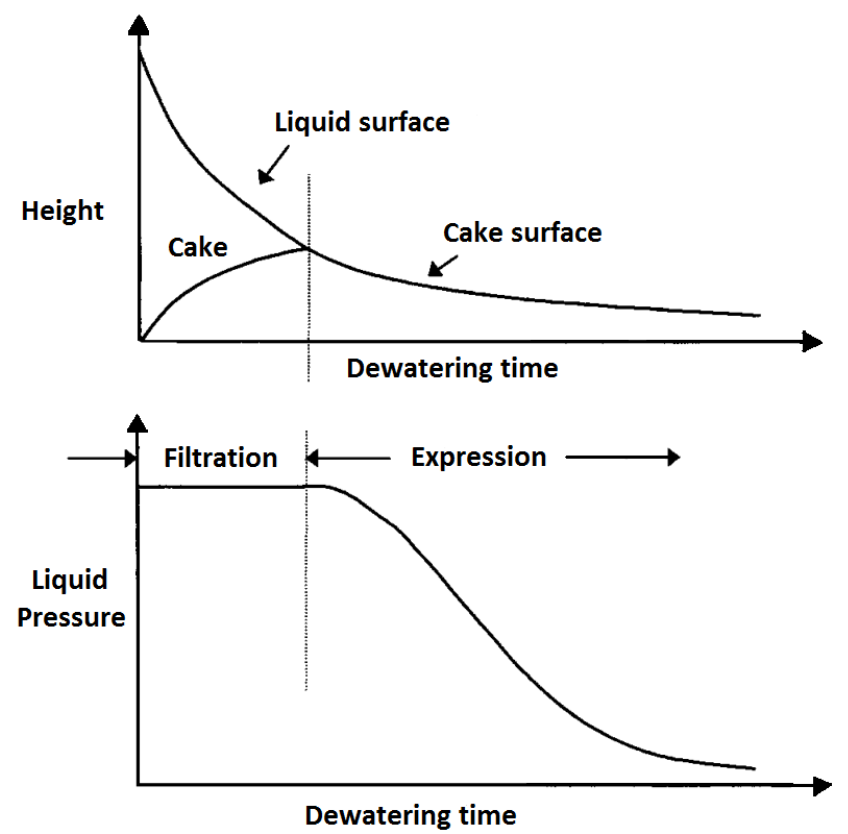

Figure 4 Two phases of sludge dewatering (Novak et al. (1999), with permission from ASCE)

This research group developed a method of measuring the rate of expression using modifications of SRF test, as described by Sørensen and Sørensen (1997). The procedure consisted of 2 steps - gravity drainage and expression. The normalized liquid pressure, defined as the ratio of the liquid to total pressure $\left(\mathrm{p}_{1} / \mathrm{p}_{\text {total }}\right)$, was measured with time until it reached plateau in the expression phase. Effects of applied pressure, cake thickness and compressibility and conditioner choice on expression were also investigated. The study results highlighted that $\mathrm{p}_{1} / \mathrm{p}_{\text {total }}$ was an excellent indicator for the extended phase of dewatering. In addition, a relationship of $\mathrm{p}_{1} / \mathrm{p}_{\text {total }}$ with cake solid concentration was also established for both conditioned and unconditioned sludge, which revealed that the ultimate dry solids content was the same for all cases. However, the major difference was the amount of time in which the maximum solids cake could be achieved in each case, which means the difference in the rate of dewatering process.

Similar to the work conducted by Novak's group, Tastu (2007) presented a two-step method (filtration and pressing steps) to characterize sludge dewatering properties as described by Bouskova and la Cour Jansen (2006) and Bouskova et al. (2006). The dry solid content of sludge after filtration $\left(\mathrm{DS}_{\text {filtr }}\right)$ and expression $\left(\mathrm{DS}_{\text {press }}\right)$ steps were employed to characterize sludge filterability and compressibility, respectively.

Both lab-scale and full-scale results of the study demonstrated that $\mathrm{DS}_{\text {press }}$ seems to be a good characterization parameter of sludge compressibility as well as good indicator of sludge dewaterability. However, the study failed to characterize sludge filterability using $\mathrm{DS}_{\text {filtr }}$. Thus, it was concluded that filtration step could only considered as a way to prepare sludge for the pressing stage in this study. Another limitation of the method was that the measures of $\mathrm{DS}_{\text {filtr }}$ and $\mathrm{DS}_{\text {press }}$ were sensitive to the filtration time and the amount of sludge used for measurement. 
In general, these two techniques were developed for filtration. It has been noted that the procedures used the solid content of sludge cake to indicate dewatering efficiency, which targeted the most important purpose of dewatering process. On the other hand, like all traditional SRF tests, the above two methods experienced problems with setting suitable operational parameters such as filtration time, the measured amount of sludge and applied pressure. As a result, more studies should be done to develop a comprehensive method for sludge dewatering characterization.

\section{Dewaterability indicators for centrifugation processes}

Apart from filtration devices, centrifuge has been used widely for sludge dewatering and has become increasingly popular by virtue of its high performance in producing higher cake solids content that can be up to $30 \%$ for dewatering of anaerobically digested biosolids (Higgins et al. 2006). As a consequence of differences in operation and conditioning requirements, filtration and centrifugation effectiveness should be evaluated separately. It has been proven that numerous factors influence centrifugability and various attempts have been made to determine reliable indicators for sludge centrifugation performance. However, no appropriate parameter has yet been developed due to difficulties in reproducing the processes taking place inside the full-scale centrifuge in the laboratory context (Spinosa \& Mininni 1984). Unlike filtration types, filter skin formation of sludge during filtration which leads to the extended phase of dewatering, may not occur in the centrifugal process. Therefore, Novak et al. (1999) suggested that a theoretical assessment of the stresses on sludge during dewatering would be useful in the case of centrifuge. Besides, as mentioned earlier, one of the crucial roles of dewatering process is to increase the solid content of sludge in order to reduce sludge volume. Consequently, cake solids content should be defined as a parameter representing the process's efficiency. For centrifuge, it is generally classified that dewatered sludge having a dry solid content of theoretically about $26-30 \%$, which is commonly $20-25 \%$ in the industrial scale, indicates for a good dewatering performance. On the other hand, solids concentration of $8-22 \%$ is considered as bad dewaterability (Vigneswaran \& Aim 1989).

\section{Settleability, scrollability and floc strength}

Regarding operations of filter presses or belt presses which apply compression for sludge dewatering (Figure 5a), filterability is mainly used to evaluate the process performance. On the other hand, for centrifuges, centrifugabilty which indicates the ability to dewater sludge by centrifugation (Spinosa \& Mininni 1984) could be defined as the ease of being conveyed by the screw of the feeding sludge (Figure 5). Spinosa and Mininni (1984), as a consequence, reported that sludge settleability, scrollability and floc strength were major sludge characteristics influencing centrifugability. Unfortunately, no standard methods are available in which the above properties are considered as a whole. Nonetheless, Vesilind (1970) introduced a technique for measuring settling and scrolling properties of sludge using a lab-centrifuge and a standard penetrometer. However, in many cases, the technique has proved to be unreliable for activated sludge. Aveni and Lamarca (1974), who undertook comparative tests on both laboratory and full-scale devices, discovered relatively good relationships between the two cases in terms of percentage solids recovery. 


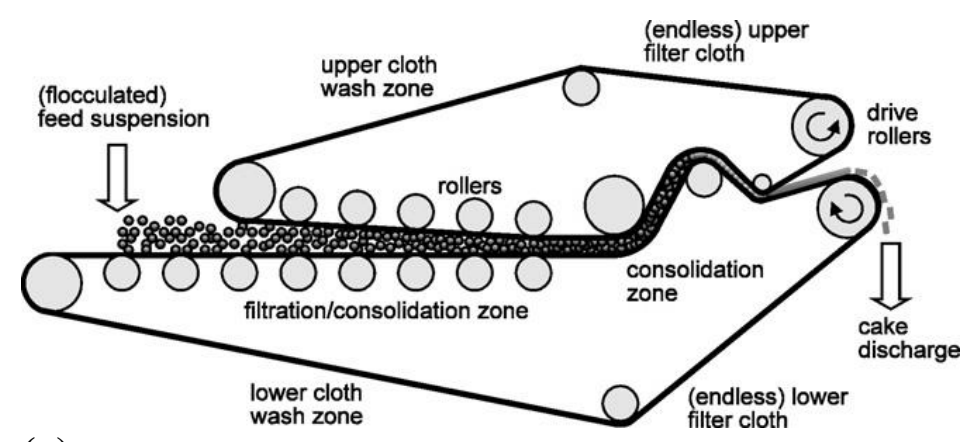

(a)

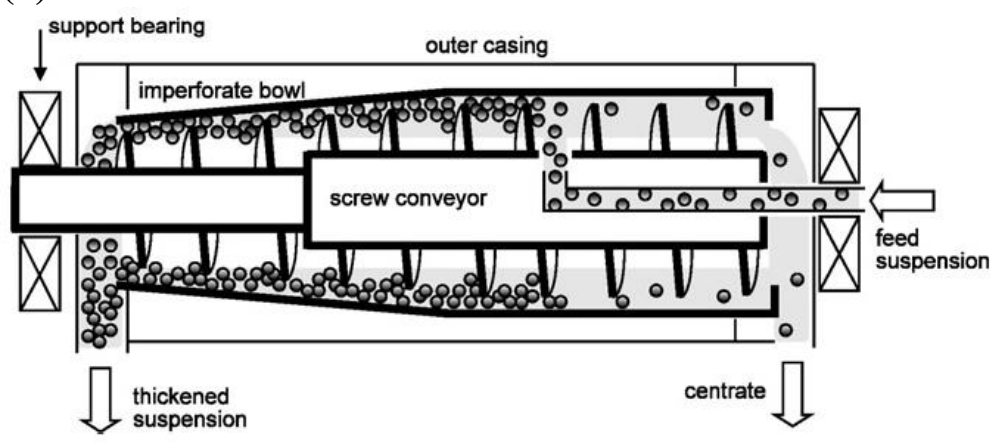

(b)

Figure 5 The schematic diagrams of (a) belt press filter and (b) centrifuge (reprinted from Wakeman (2007) with permission from Elsevier)

The method of floc strength measurement allows the sludge flocs' specific resistance to centrifugation to be evaluated (Spinosa \& Mininni 1984). This method was carried out by measuring the CST of the stirred sludge at $1000 \mathrm{rpm}$ for different stirring times. The study concluded that a clear centrate can be obtained when the plot of CST versus stirring time is linear with a slight slope, between 10 and $100 \mathrm{~s}$, and the CST value at 10s stirring is around 10 $-12 \mathrm{~s}$.

\section{Compactibility}

Compactibility, which was defined as cake solids content of sludge after centrifugation, has been used by a number of studies (Erdincler \& Vesilind 2000; Emir 2002; Emir \& Erdincler 2006) to indicate sludge dewaterability along with conventional dewatering indices. Compactibility was evaluated by centrifuging sludge samples. Following this the degree of compaction was determined in terms of solids cake content of the compacted samples and the height of the compacted sludge layer. Emir and Erdincler (2006) stated that compactibility is a useful measure to assess dewaterability of hard-to-filter sludges. They also suggested the use of this parameter together with CST and SRF to identify the most suitable dewatering method for a given sludge. Nevertheless, their methods cannot quantify the stress imparted on sludge cake during dewatering by centrifuge. Chu and Lee (2001) introduced an arm-suspended centrifuge (Figure 5) to investigate the centrifugal separation of moisture from conditioned activated sludge and determine an optimal rotational speed for maximum moisture removal. However, the final cake solids achievable cannot be predicted using this method. 


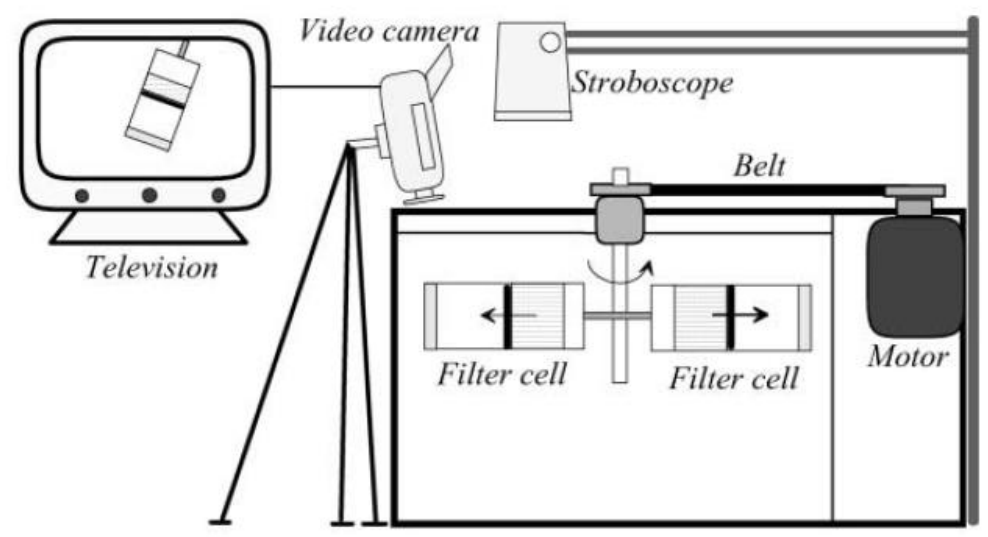

Figure 6 Schematics of the arm-suspended centrifuge (reprinted from Chu \& Lee (2001) with permission from Elsevier)

\section{Modified centrifugal index (MCI) - A new centrifuge based laboratory scale sludge dewatering}

It was found that the stresses imparted to sludge during dewatering have a significant impact on dewatering efficiency in terms of solids cake content. Higgins et al. (2006) utilized Gt value in determining the effect of shear or mixing intensity on OPD using a calibrated lab-scale mixer. Here, $G$ was velocity gradient $\left(\mathrm{s}^{-1}\right)$ and $\mathrm{t}$ is time of mixing ( $\mathrm{s}$ ). By using this dimensionless parameter, they determined the stress of full-scale dewatering devices using shear stress as equivalent. However, there is a major drawback that the final cake solids achievable at full-scale cannot be predicted with this bench-scale method (Dentel \& Dursun 2009). Besides, the shear imparted on the sludge cake during dewatering is different from that applied to the sludge liquid during conditioning.

Recently, a modified lab-scale centrifuge device, namely modified centrifugal index (MCI) was suggested and investigated to overcome the difficulties encountered in the traditional dewaterability indicators. The method proposed by Higgins and colleagues at Bucknell University (Higgins et al. 2014) has been used by To et al. ( 2014) to evaluate the sludge dewaterability of centrifugation. The stress of centrifuge, or the centrifugal force, is measured using a dimensionless parameter gt, which is the product of times gravity $\mathrm{g}$ (which is related to centrifuge rotating speed and rotor radius) and centrifugation time $t$ (s).
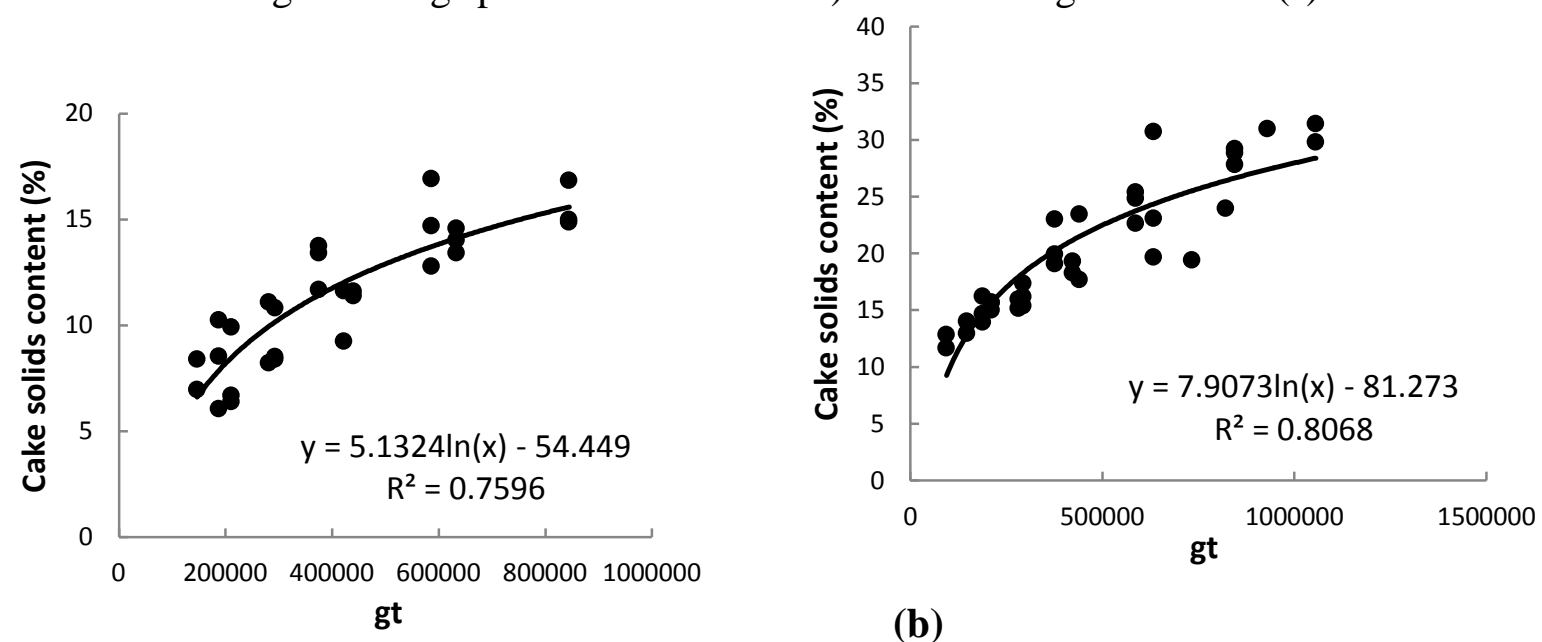

(a)

Figure 7 Cake solids of (a) unconditioned sludge and (b) conditioned sludge after centrifuge as a function of gt values (To et al. 2014) 
Figure 7 illustrates plots of cake solids content of unconditioned and conditioned sludge at different gt values. These graphs indicate that the increase in gt results in the improvement of cake solids, which implies that higher the centrifugation intensity, the better the dewatering properties will be in terms of cake solids. However, beyond a certain value of gt, the percentage of cake solids remained almost the same despite increasing intensity. Furthermore, it was noticed that without conditioning, the maximum cake solid achievable by centrifuge was only about $16 \%$ (Figure 7a). After conditioning, this cake solid increased to around 30\% (Figure 7b), which is quite similar to the dewatered sludge concentration at the wastewater treatment plant studied. This demonstrates that MCI test can be effective in estimating the final cake concentration as well as simulating the real dewatering process. In addition, one notes from Figure 7 that the maximum solid cake achieved without conditioning (Figure 7a) can be obtained at a much lower gt value when conditioning was employed (Figure 7b). It illustrated the positive effect of polymer conditioning treatment prior to dewatering. This method has the potential to determine the optimal polymer dose in sludge conditioning. However, this study only worked on anaerobically digested sludge. Therefore, further studies for other sludge types are required to prove this concept.

\section{Other dewaterability measurement techniques}

\section{Moisture distribution}

Sewage sludge is hydrophilic by character and typically has 98 to $99.7 \%$ moisture content which is generally difficult to remove (Smollen 1990). Reducing sludge volume is basically achieved by maximizing the cake solid content, or in another words, minimizing the water content. Hence, a comprehensive understanding of water distribution in sludge and their relationship to sludge dewaterability may be useful for improving the dewatering system's performance.

\section{Water classification and measurement techniques}

The presence of solids causes the non-homogeneity of water within sludge, leading to different types of water with different behaviours (Vesilind 1994). Several researchers proposed a number of ways to classify water and most of them based on the interaction energy binding or structural binding between water molecules and solid materials (Yin et al. 2004). Vaxelaire and Cézac (2004) reviewed moisture distribution in different activated sludge and reported comprehensively various ways of water classifications. The most popularly used categorization was devised by Vesilind and Hsu (Vesilind \& Hsu 1997), which defined four types of water in sludge (Figure 8) as follows:

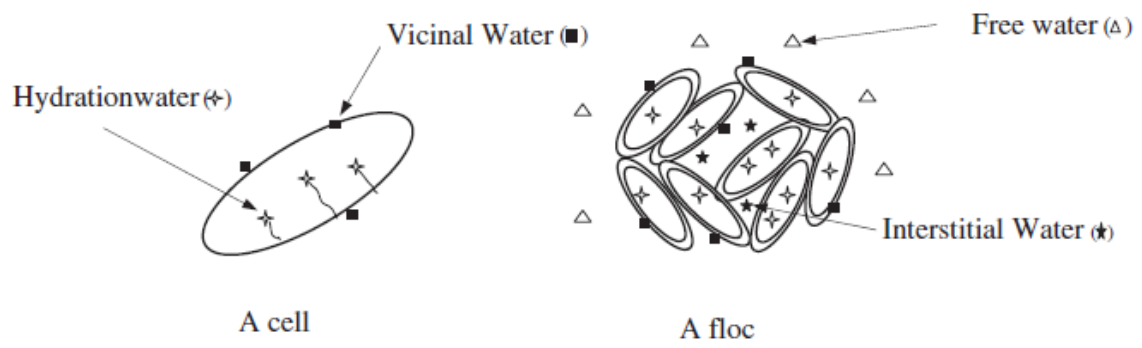

Figure 8 Schematic model of various forms of water in biosludge (reprinted from Mowla et al. (2013) with permission from Elsevier) 
- Free water: water not associated with solid particles and is separated easily by simple gravitational settling.

- Interstitial water: water trapped inside floc structure or a cell and only a small amount of this water might be removed by mechanical dewatering devices such as vacuum filters or centrifuges.

- Surface (or vicinal) water: water physically held on to the surface of solid particles by adsorption and adhesion and cannot be separated by any mechanical means.

- Hydration water: water chemically bound to the solids particles and can be released only by thermo-chemical destruction of the particles at temperature above $105^{\circ} \mathrm{C}$.

Another more simple classification is to divide water into two main types: firstly, free water which is not influenced by solid particles; and secondly, bound water properties which are modified due to the presence of solid particles. The bound water content is deemed to be one of the major limiting factors affecting sludge dewatering efficiency because removing it requires much larger amounts of energy. Over the year, various techniques have been proposed to measure the moisture distribution in general and the bound water content in particular. These have been compared and discussed in terms of operating conditions by Vaxelaire and Cézac (2004). Among these techniques, the most commonly used are:

- Drying test: this test is based on the analysis of a drying curve with an assumption that the rate of evaporation of the waters depends on the type of bond between water and the solid particles.

- Dilatometry: this technique is based on freezing properties of waters, which measures the freezable water (free water) content by using dilatometer placed at $-20^{\circ} \mathrm{C}$. The difference between total water content and the free water content is considered to be bound water.

- Expression test: this method is mainly used to measure bound water content which is defined as the final moisture content of sludge expressed under a very high constant pressure (generally around $31 \mathrm{MPa}$ ).

- Centrifugal settling test: in this test, sludge is centrifuged at very high rotational speeds of $3500-4000 \mathrm{rpm}$ and the water content of sludge sediment is reported as bound water content.

- Differential thermal analysis (DTA) and Differential scanning calorimetry (DSC): both techniques assume that bound water does not freeze below the given threshold temperature such as $-20^{\circ} \mathrm{C}$. DTA and DSC, respectively, measure the temperature difference and the flow heat difference between sample and a thermally inert material (reference material) (Erdincler \& Vesilind 2003; Lee \& Lee 2004; Deng et al.2011). These two methods can be considered as fast and valuable tools for bound water determination (Katsiris \& Kouzeli-Katsiri 1987), however, Lee \& Hsu (1995) pointed out that they are not practical for measuring the water distribution of activated sludge due to the sludge's non-uniformity. Furthermore, the selection of threshold temperature is essentially important since it is used for distinguishing the free and bound water (Lee \& Lee 1995). As a result, DTA or DSC performed simultaneously with Thermogravimetric analysis (TGA) (aslo known as TG-DTA and TG-DSC), as proposed by Chen et al. (1997) and Ferrasse \& Lecomte (2004), for biological products.

It is notable that these techniques imitate different methods of sludge dewatering such as drying beds (drying test), freezing beds (dilatometry), filter presses (expression test) and centrifuges (centrifugal settling test). However, different techniques with different principles have led to difficulties in comparing results of different studies. It is also evident that the various definitions of water types can cause some confusion. 


\section{Moisture content and sludge conditioning and dewatering}

Using moisture content to assess sludge dewatering efficiency is an interesting and promising approach that has attracted the attention of numerous researchers. Many have concentrated on determining the correlation between moisture distribution and sludge conditioning and dewatering.

In terms of conditioning, it has been demonstrated by a number of authors that adding conditioner leads to a significant reduction of the bound water content, demonstrating the positive effect of chemical conditioning on water distribution (Halde 1979; Carberry \& Prestowitz 1985). However, overdosed conditioning may cause an increase in bound water due to the absorption of moisture onto the polymer particles (Chu \& Lee 1999).

For dewatering, a relationship between dewatering energy requirement and sludge water content (Figure 9 shows that only about $20 \%$ of water is easily removed, even for conditioned sludge, but once water content is reduced to below $80 \%$, the dewatering energy demand dramatically increases (Lee \& Hsu 1994; Chu \& Lee 1999; Wang et al. 2010). This implies that the sludge can no longer be mechanically dewatered to obtain a smaller residual water content, which is also considered to be the limit of sludge mechanical dewatering. Several studies that identified of the correlations between water distribution and sludge dewaterability concluded that results actually depended on the measurement techniques used. For instance, when using the drying test for measurement, no significant correlation was obtained with CST and cake solid content (Smollen 1990). In the meantime, strong correlations with SRF (Robinson \& Knocke 1992) and cake solids content (Heukelekian \& Weisberg 1956; Forster \& Lewin 1972) were detected when using dilatometry technique.

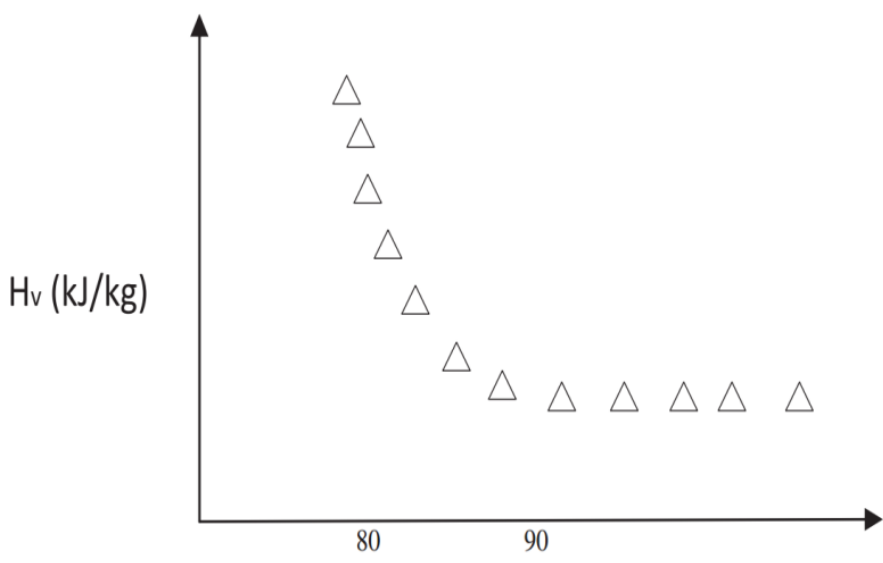

Water content $\%$

Figure 9 Relationship between sludge water content and dewatering energy demand (reprinted from Mowla et al. (2013) with permission from Elsevier)

Apart from being a parameter used for assessing sludge conditioning and dewatering efficiency prediction, the profile of moisture distribution within sludge may provide useful information for choosing the dewatering methods of a specific sludge. For example, sludge with low immobilised moisture content could be dewatered effectively by drying beds while sludge with high immobilised moisture should be dewatered using high pressure equipment such as filter presses or centrifuges (Smollen 1990). 


\section{Rheology}

\section{Rheology and sludge characterization}

Rheology is the science that deals with the flow and deformation of fluids and solids under the influence of stresses and it has become an increasingly important tool in characterizing waste sludge, especially sewage sludge (Abu-Orf \& Dentel 1999; Örmeci 2007). Although the first studies on rheological behaviour of sewage sludge were conducted since in the 1930s, most of them were motivated by the need to predict pumping requirements. More recent studies have focused on examining the rheology in relation to sludge dewaterability with the aim to predict, control and optimize conditioning and dewatering processes (Marinetti et al. 2010).

The rheological behaviours of a certain fluid can be schematically described by flow curves, also known as rheograms. Sewage sludge is generally classified as non-Newtonian fluid with shear thinning (pseudoplastic) behaviour and a thixotropic nature, leading to its highly complicated rheological characteristics (Klinksieg et al. 2007). Several mathematical models, which were mostly based on relationships between shear stress and shear rate, were proposed to quantify the fluid rheology. Viscosity is the most basic rheological parameter. Viscosity of the Newtonian system is constant for all shear rates while for sewage sludge, which is a non-Newtonian system, it is a function of shear rate (Hiemenz 1986). Another typical rheology parameter is yield stress, which is roughly defined as an initial or minimum stress applied on material to induce true flow. The concept of yield stress and viscosity in relation to sludge conditioning and dewatering have limited usefulness due to difficulties in defining the terms involved in. Furthermore, it is not meaningful to compare values of different studies, unless an adequate description of sludge types and conditioning methods are specified. Besides these two, the maximum shear stress $\left(\tau_{\max }\right)$, indicative of the force needed to rupture structure bonds between the polymer and sludge flocs, may possibly be used to determine OPD along with yield stress (Marinetti et al. 2010).

\section{Rheology and sludge conditioning}

The operation of sludge conditioning has direct and profound effects on sludge rheology. For example, the use of polymers, especially high molecular weight ones, for flocculating sludge significantly impacts on the viscosity via increases in both floc volume and floc strength (Dentel 1997). For this reason, Dick and Ewing (1967) suggested that sludge rheological parameters could be used as a guide for evaluation and control of conditioning efficiency.

Various researchers have employed rheograms of conditioned sludge with different polymer doses for determining the OPD (Örmeci 2007). Figure 10 displays two commonly used types of rheograms for polymer dose assessment, shear stress-shear rate (Figure 10a) and torque-time curves (Figure 10b). The former curves are obtained by using concentric-cylinder rheometer, also known as coaxial rotational viscometer (Dick \& Ewing 1967; Campbell \& Crescuolo 1982; Dick \& Buck 1985) while the latter curves are obtained by the use of torque rheometer which were developed as a response for problems associated with the former (Örmeci \& Abu-Orf 2004; Ormeci \& Abu-Orf 2006; Örmeci 2007). Both rheograms show similar curves exhibiting either a definite peak or a portion where the slope is approaching zero. This peak indicates the point where elastic floc network bonds rupture and the higher the peak, the more energy is needed to break up the flocs (Langer et al. 1994; Abu-Orf \& Dentel 1999). Operational conditioning parameters which maximized the height of the peak are selected as optimum. The difference between these two methods is that concentric-cylinder rheometer only permits the deflocculation phase to be observed. In contrast, the torque-time 
rheogram shows both flocculation and deflocculation phases since polymer injection into sludge occurs during torque measurements (Örmeci 2007). Moreover, the torque rheometer has been proved to have higher reproducibility than shear stress - shear rate rheograms, and they can eliminate the need for taking sub-samples from conditioned sludges (Örmeci \& Abu-Orf 2004).

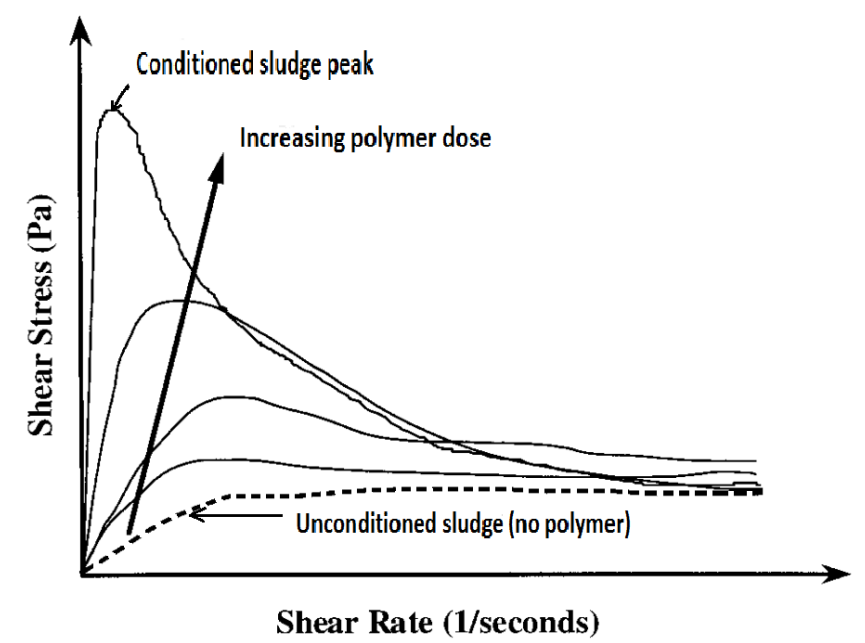

(a)

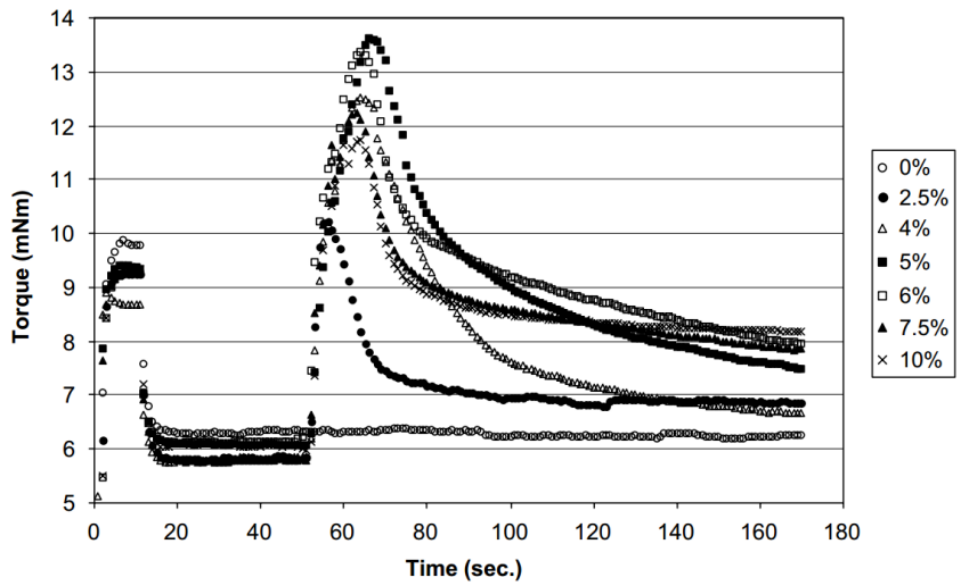

(b)

Figure 10 (a) Shear stress - shear rate rheogram (Abu-Orf \& Dentel (1999), with permission from ASCE) and (b) Torque rheogram of unconditioned and conditioned sludge with different polymer doses (reprinted from Örmeci (2007) with permission from Elsevier)

Several previous studies presented two methods based on torque rheology that can allow not only the OPD and mixing conditions to be determined but also the best performing polymers to be selected (Örmeci 2007). The first method uses unconditioned sludge and utilizes the peaks observed immediately after polymer injection. This is useful for determining OPD. The second method uses conditioned sludge and utilizes the whole torque rheograms, which is suitable for comparing rheological and dewatering characteristics of conditioned sludges (Abu-Orf \& Örmeci 2005; Örmeci \& Abu-Orf 2005). Apart from rheograms, Campbell and Crescuolo (1983) suggested that instantaneous viscosity, which is derived from the torque or shear stressshear rate curves, could also be used to control sludge conditioning. Another promising method using rheology properties to improve the sludge processing is monitoring the filtrate or centrate (liquid stream) viscosity following mechanical dewatering by viscometer or rheometer (Christensen et al. 1993; Dentel \& Abu-Orf 1995). 


\section{Rheology and sludge dewatering}

It is accepted that cake solids and suspended solids (SS) contents in centrate or filtrate are two major parameters used to determine the effectiveness of dewatering operations. High cake solids content and low level of solids recovery mean that the dewatering process is functioning well (Sanin et al. 2011). However, traditional dewatering measurements only assess the former and do not report on the latter. Rheological characteristics are indicative of floc strength; therefore, it could be useful for evaluation of sludge dewatering efficiency with reference to both criteria. Many researchers have been working on correlating the rheological properties, i.e. viscosity and yield strength, with the sludge characteristics such as TS, SS, particle surfaces and CST (Dick \& Ewing 1967; Forster 1981; Spinosa et al. 1989; Christensen et al. 1993). Klinksieg et al. (2007) reported a good correlation between full-scale dewatering cake and rheological properties (at a shear stress of $500 \mathrm{~s}^{-1}$ ). Most of the rheology studies on the topic of dewaterability were based on determining relationships between floc strength or network strength and sludge dewatering properties (Abu-Orf \& Dentel 1997; Abu-Orf \& Dentel 1999; Yen et al. 2002; Hou \& Li 2003; Dentel \& Dursun 2009; Marinetti et al. 2010). However, none provided a strong correlation between rheological parameters and sludge dewaterability as measured by standard test methods.

Several new rheological approaches are network strength measurement (Yen et al. 2002; Örmeci \& Abu-Orf 2004), dynamic oscillatory tests (Mori et al. 2006; Dentel \& Dursun 2009), creep tests (Baudez \& Coussot 2001) and immobilization cell rheometry (Ayol et al. 2010). These methods could be advanced in providing a realistic model of sludge behaviour during conditioning and dewatering. For example, oscillatory tests with two parameters known as the storage modulus $\left(G^{\prime}\right)$ and loss modulus $\left(G^{\prime \prime}\right)$ help to determine the sludge behaviour is gel like or dispersion - like by comparing these values (Dentel 2004).

\section{Summary}

Evaluation of sludge dewaterability is critically necessary for any sludge treatment system where optimizing the dewatering process is the aim. However, this work is relatively challenging due to the unpredictable and elusive behaviour of all sludge types, especially biosludge as well as variations in solid-liquid separation methods. Since the establishment of the very first dewatering indices, various indicators for dewatering process have been developed and applied over the years in tandem with dewatering technology. Despite these advances, there is as yet no universal dewatering index which can fully reflect the ability to dewater sludge. It is believed that a reliable dewatering index should not only simulate the real water extraction process but also estimate the maximum solid content of sludge cake achievable. Conventional dewatering indices seem to lack one or both of these, and consequently they hardly express the efficiency of dewatering properly.

SRF, while it was cumbersome in equipment and proved to be time-consuming, can nonetheless estimate the cake solid content of sludge after filtration. On the other hand, CST is increasingly popular due to its ease of measurement; however, it fails to predict solid concentration of dewatered cake. In fact, CST and SRF may be correlated strongly with free water (Peng et al. 2011), which constitutes only $20 \%$ of total water content (Mowla et al. 2013). On the other hand, bound water content because it takes up the bulk of sludge total moisture content, should also be taken into consideration. It is therefore suggested that to properly evaluate the dewatering efficiency of sludge, different parameters should be included. 
For example, CST and SRF, which often serve to register dewatering rate, could be combined with bound water or cake solids content and this will indicate the extent of dewatering.

Rheology represents a potential powerful tool for controlling and optimizing conditioning, but it is not sufficient to predict the performance of full-scale dewatering systems. This is because the method has targeted the floc strength rather than the cake solids content. In addition, it cannot reproduce the real dewatering process. It is also suggested that along with developing accurate measurements of sludge dewatering performance, selecting a proper index for different methods of dewatering is critical.

Finally, with reference to filtration equipment, SRF is possibly the most appropriate efficiency indicator, while for centrifugation devices, compactibility and MCI are promising dewaterability measurements. The major difference between these two techniques is that the later can quantify the stress imparted on sludge during dewatering by centrifuge, which can reflect the influence of dewatering equipment on how well the solid-liquid separation process performs. However, since MCI is a new method, further studies are needed to fully assess its application to sludge dewaterability.

\section{Acknowledgement}

First author thanks to Sydney Water Corporation and UTS International Research Scholarship (IRS) for their financial supports for her study.

\section{References}

Abu-Orf, M. \& Dentel, S. 1997 Effect of mixing on the rheological characteristics of conditioned sludge: Full-scale studies. Water Science and Technology 36(11), 51-60.

Abu-Orf, M. \& Dentel, S. 1999 Rheology as Tool for Polymer Dose Assessment and Control. Journal of Environment Engineering 125(12), 1133-1141.

Abu-Orf, M. \& Örmeci, B. 2005 Measuring Sludge Network Strength Using Rheology and Relation to Dewaterability, Filtration, and Thickening-Laboratory and Full-Scale Experiments. Journal of Environment Engineering 131(8), 1139-1146.

Agarwal, S., Abu-Orf, M. \& Novak, J. T. 2005 Sequential polymer dosing for effective dewatering of ATAD sludges. Water Research 39(7), 1301-1310.

Aveni, A. \& Lamarca, V. 1974 Cooperative program on the characterization of the sludges: centrifugability-activity of the Institute di Ricerca Breda. EEC COST 68.

Ayol, A., Dentel, S. \& Filibeli, A. 2010 Rheological characterization of sludges during belt filtration dewatering using an immobilization cell. Journal of Environmental Engineering 136(9), 992-999.

Barber, J., Bullard, C. \& Charles, M. 1997 Centrifuge test predicts solids dewaterability. Ind. Wastewater 5(2), 31-36.

Baskerville, R. \& Gale, R. 1968 A simple automatic instrument for determining the filterability of sewage sludges. Water Pollution Control 67, 233-241.

Baudez, J.C. \& Coussot, P. 2001 Rheology of aging, concentrated, polymeric suspensions: application to pasty sewage sludges. Journal of Rheology (1978-present) 45(5), 1123 1139.

Bouskova, A. \& la Cour Jansen, J. 2006 Improvement of separation and dewatering of activated sludge by using enhanced biological removal process over chemical phosphorus precipitation. Journal of Residuals Science and Technology 3(3), 145-151. 
Bouskova, A., Persson, E., la Cour Jansen, J. \& Dohanyos, M. 2006 The effect of operational temperature on dewatering characteristics of digested sludge. Journal of Residuals Science and Technology 3(1), 43-49.

Campbell, H. \& Crescuolo, P. 1983 Assessment of sludge conditionability using rheological properties. In: Proceedings of an EEC Workshop on methods of Characteristics of Sewage.

Carberry, J. B. \& Prestowitz, R. A. 1985 Flocculation effects on bound water in sludges as measured by nuclear magnetic resonance spectroscopy. Applied and environmental microbiology 49(2), 365-369.

Chen, G.W., Hung, W.T., Chang, I.L., Lee, S.F. \& Lee, D.J. 1997 Continuous classification of moisture content in waste activated sludges. Journal of Environmental Engineering 123(3), 253-258.

Christensen, G. L. \& Dick, R. I. 1985 Specific resistance measurements: nonparabolic data. Journal of Environmental Engineering 111(3), 243-257.

Christensen, G. L. 1983 Units for specific resistance. Journal (Water Pollution Control Federation), 417-419.

Christensen, J. R., Sørensen, P. B., Christensen, G. L. \& Hansen, J. A. 1993 Mechanisms for overdosing in sludge conditioning. Journal of Environmental Engineering 119(1), 159171.

Chu, C. \& Lee, D. 1999 Moisture distribution in sludge: Effects of polymer conditioning. Journal of Environmental Engineering 125(4), 340-345.

Chu, C. \& Lee, D. 2001 Experimental analysis of centrifugal dewatering process of polyelectrolyte flocculated waste activated sludge. Water Research 35(10), 2377-2384.

Deng, W., Li, X., Yan, J., Wang, F., Chi, Y. \& Cen, K. 2011 Moisture distribution in sludges based on different testing methods. Journal of Environmental Science 23(5), 875-880.

Dentel, S. \& Abu-Orf, M. 1995 Laboratory and full-scale studies of liquid stream viscosity and streaming current for characterization and monitoring of dewaterability. Water Research 29(12), 2663-2672.

Dentel, S. \& Dursun, D. 2009 Shear sensitivity of digested sludge: Comparison of methods and application in conditioning and dewatering. Water Research 43(18), 4617-4625.

Dentel, S. 1997 Evaluation and role of rheological properties in sludge management. Water Science and Technology 36(11), 1-8.

Dentel, S. 2004 Landmark Advances in Sludge Conditioning and Dewatering. In: 2nd IWA Leading-Edge Conference on Water and Wastewater Treatment Technologies, p. 281.

Dick, R. I. \& Buck, J. H. 1985 Measurement of activated sludge rheology. In: Environmental Engineering, ASCE, 539-545.

Dick, R. I. \& Ewing, B. B. 1967 The rheology of activated sludge. Journal (Water Pollution Control Federation), 543-560.

Emir, E. \& Erdincler, A. 2006 The role of compactibility in liquidsolid separation of wastewater sludges. Water Science and Technology 53(7), 121-126.

Emir, E. Ü. 2002The Role of Dewaterability Measures on the Liquid-solid Separation of Biological Sludges: Compactibility as a New Measure of Sludge Dewaterability. Bogazici University, Istanbul, Turkey.

Erdincler, A. \& Vesilind, P. 2000 Effect of sludge cell disruption on compactibility ofbiological sludges. Water Science and Technology 42(9), 119-126.

Erdincler, A. \& Vesilind, P.A. 2003 Effect of sludge water distribution on the liquid-solid separation of a biological sludge. Journal of Environmental Science and Health 38(10), 2391-2400. 
Ferrasse, J.H. \& Lecomte, D. 2004 Simultaneous heat-flow differential calorimetry and thermogravimetry for fast determination of sorption isotherms and heat of sorption in environemental or food engineering. Chemical Engineering Science 59(6), 1365-1376.

Forster, C. \& Lewin, D. 1972 Polymer interactions at activated sludge surfaces. Effluent and Water treatment journal 12(10).

Forster, C. 1981 Preliminary studies on the relationship between sewage sludge viscosities and the nature of the surfaces of the component particles. Biotechnology Letters 3(12), 707712.

Gale, R. 1967 Filtration theory with special reference to sewage sludges. Water pollution control 66(6), 622-632.

Graham, T. M. 1999Predicting the performance of belt filter presses using the Crown Press for laboratory simulation, DTIC Document, College of Engineering and Science, Clemson University, South Carolina.

Halde, R. 1979 Sewage sludge characterization by vacuum drying. Filtration and Separation 16(3), 238-242.

Herwijn, A. J., Heij, E. J. L., IJzermans, J. J., Coumans, W. J. \& Kerkhof, P. J. 1995 Determination of specific cake resistance with a new capillary suction time apparatus. Industrial and Engineering Chemistry Research 34(4), 1310-1319.

Heukelekian, H. \& Weisberg, E. 1956 Bound water and activated sludge bulking. Sewage and Industrial Wastes, 558-574.

Hiemenz, P. 1986 Principles of colloid and surface chemistry. Marcel Decker, New York.

Higgins, M. J., Bott, C. \& Schauer, P. 2014 Does Bio-P Impact Dewatering after Anaerobic Digestion? In: 2014 Water Env. Federation Annual Conference, Austin, Texas.

Higgins, M. J., Chen, Y. C. \& Murthy, S. N. 2006Understanding factors affecting polymer demand for conditioning and dewatering, Water Environment Research Foundation.

Hou, C. H. \& Li, K. C. 2003 Assessment of sludge dewaterability using rheological properties. Journal of the Chinese Institute of Engineers 26(2), 221-226.

Katsiris, N. \& Kouzeli-Katsiri, A. 1987 Bound water content of biological sludges in relationship to filtration and dewatering. Water Research 21(116), 1319-1327.

Klinksieg, K., Moshage, U. \& Dichtl, N. 2007 Rheology and dewaterability of municipal sewage sludge. In: Moving Forward Wastewater Biosolids Sustainability: Technical, Managerial and Public Synergy, IWA, Moncton New Brunswick, Canada, p. 155.

Konnur, P. 2008Model ICT Practices in Librarianship. Indian Academic Library Association.

Langer, S. J., Klute, R. \& Hahn, H. H. 1994 Mechanisms of floc suspensions-III. The elastic flow model. Journal of Colloid and Interface Science 57(2), 10.

Lee, D. \& Hsu, Y. 1994 Use of capillary suction apparatus for estimating the averaged specific resistance of filtration cake. Journal of Chemical Technology and Biotechnology 59(1), 45-51.

Lee, D.J \& Lee, S.F. 1995 Measurement of bound water content in sludge: the use of differential scanning calorimetry (DSC). Journal of Chemical Technology and Biotechnology 62, 359-365.

Lee, D.J. \& Hsu, Y.H. 1995 Measurement of bound water in sludges: a comparative study. Water Environmental Research 67(3), 310-317.

Lee, D.J. \& Wang, C.H. 2000 Review paper: Theories of cake filtration and consolidationand implications to sluge dewatering. Water Research 34(1), 1-20.

Marinetti, M., Dentel, S., Malpei, F. \& Bonomo, L. 2010 Assessment of rheological methods for a correlation to sludge filterability. Water Research 44(18), 5398-5406.

Marinetti, M., Malpei, F. \& Bonomo, L. 2009 Relevance of expression phase in dewatering of sludge with chamber filter presses. Journal of Environmental Engineering 135(12), $1380-1387$. 
Mori, M., Seyssiecq, I. \& Roche, N. 2006 Rheological measurements of sewage sludge for various solids concentrations and geometry. Process Biochemistry 41(7), 1656-1662.

Mowla, D., Tran, H. \& Allen, D. G. 2013 A review of the properties of biosludge and its relevance to enhanced dewatering processes. Biomass and Bioenergy 58, 365-378.

Notebaert, F., Wilms, D. \& Van Haute, A. 1975 A new deduction with a larger application of the specific resistance to filtration of sludges. Water Research 9(7), 667-673.

Novak, J. T. 2006 Dewatering of sewage sludge. Drying Technology 24(10), 1257-1262.

Novak, J. T., Agerbæk, M. L., Sørensen, B. L., Hansen \& Aa, J. 1999 Conditioning, filtering, and expressing waste activated sludge. Journal of Environmental Engineering 125(9), 816-824.

Olivier, J., Vaxelaire, J. \& Vorobiev, E. 2007 Modelling of cake filtration: An overview. Separation Science and Technology 42, 1667-1700.

Örmeci, B. \& Abu-Orf, M. 2004 Estimation of optimum polymer dose using the area under a torque-time rheogram (totalized torque). In: Proceedings of the IWA World Water Congress, Marrakech, Morocco.

Örmeci, B. \& Abu-Orf, M. 2005 Protocol for measuring comparative sludge network strengthRelation to dewaterability. ASCE Journal of Environmental Engineering 131(1), 80-85.

Örmeci, B. 2007 Optimization of a full-scale dewatering operation based on the rheological characteristics of wastewater sludge. Water Research 41(6), 1243-1252.

Örmeci, B.\& Abu-Orf, M. 2006 Using torque rheology for the identification of the optimum polymer dose and the best performing polymer. Journal of Residuals Science and Technology 3(4), 227-232.

Pan, J. R., Huang, C., Cherng, M., Li, K. C. \& Lin, C. F. 2003 Correlation between dewatering index and dewatering performance of three mechanical dewatering devices. Advances in Environmental Research7(3), 599-602.

Peng, G., Ye, F. \& Li, Y. 2011 Comparative investigation of parameters for determining the dewaterability of activated sludge. Water Environment Research 83(7), 667-671.

Reichmann, B. \& Tomas, J. 2001 Expression behaviour of fine particle suspensions and consolidated cake strength. Powder Technology 121, 182-189.

Robinson, J. \& Knocke, W. R. 1992 Use of dilatometric and drying techniques for assessing sludge dewatering characteristics. Water Environment Research, 60-68.

Sanin, F. D., Clarkson, W. W. \& Vesilind, P. A. 2011Sludge engineering: The treatment and disposal of wastewater sludges. DEStech Publications, Inc., Pennsylvania

Saveyn, H., Meersseman, S., Thas, O. \& Van der Meeren, P. 2005 Influence of polyelectrolyte characteristics on pressure-driven activated sludge dewatering. Colloids and Surfaces A 262, 40-51.

Sawalha, O. \& Scholz, M. 2007 Assessment of capillary suction time (CST) test methodologies. Environmental Technology 28(12), 1377-1386.

Sawalha, O. \& Scholz, M. 2010 Modeling the relationship between capillary suction time and specific resistance to filtration. Journal of Environmental Engineering 136(9), 983-991.

Scholz, M. 2005 Review of recent trends in capillary suction time (CST) dewaterability testing research. Industrial and Engineering Chemistry Research 44(22), 8157-8163.

Smollen, M. 1990 Evaluation of municipal sludge drying and dewatering with respect to sludge volume reduction. Water Science and Technology 22(12), 153-161.

Sørensen, B. L. \& Sørensen, P. B. 1997 Structure compression in cake filtration. Journal of Environmental Engineering 123(4), 345-353.

Spinosa, L. \& Mininni, G. 1984 Assessment of sludge centrifugability. In: Methods of Characterization of Sewage Sludges Casey TJ, L'Hermite P and Newman PJ (eds), D. Reidel Publishing Company, Dublin, Eire, 16-30. 
Spinosa, L., Santori, M. \& Lotito V. 1989 Rheological characterization of sewage sludges. Recycling von klarschlamm 2, 177.

Subramanian, S. 2005 Digestion processes and their effect on dewatering and Bound water content of sludge. MS Thesis submitted at Virginia Tech, Virginia Polytechnic Institute and State University, Virginia

Tastu, Y. 2007 Evaluation of sludge dewatering properties. MS Thesis, Faculty of Engineering, Lund University, Lund

Tebbutt, T. 1970 A note on the units of specific resistance to filtration. Water Pollution Control (GB) 69, 694.

Tenney, M. W., Echelberger, Jr W. F., Coffey, J. J. \& McAloon, T. J. 1970 Chemical conditioning of biological sludges for vacuum filtration. Journal (Water Pollution Control Federation), R1-R20.

To, V. H. P., Nguyen, T. V., Vigneswaran, S., Nghiem, L., Murthy, S., Bustamante, H. \& Higgins, M. J. 2014 Modified centrifugal index and sludge characteristics in assessing sludge dewatering (accepted). In: IWA International Young Water Professional Conference, Taipei, Taiwan.

Vaxelaire, J. \& Cézac, P. 2004 Moisture distribution in activated sludges: a review. Water Research 38(9), 2215-2230.

Vesilind, P. \& Hsu, C. 1997 Limits of sludge dewaterability. Water Science and Technology 36(11), 87-91.

Vesilind, P. 1970 Estimation of sludge centrifuge performance. Journal of the Sanitary Engineering Division 96(3), 805-818.

Vesilind, P. 1988 Capillary suction time as a fundamental measure of sludge dewaterability. Journal (Water Pollution Control Federation), 215-220.

Vesilind, P. 1994 The role of water in sludge dewatering. Water Environment Research, 4-11.

Vesilind, P. 2000 A modified capillary suction time apparatus for measuring thefilterability of super-flocculated sludges. Water Science and Technology 42(9), 135-139.

Vigneswaran, S. \& Aim, R. B. 1989 Water, wastewater, and sludge filtration. CRC Press.

Wakeman, R. J. 2007 Separation technologies for sludge dewatering. Journal of Hazardous materials 144(3), 614-619.

Wang, W., Luo, Y. \& Qiao, W. 2010 Possible solutions for sludge dewatering in China. Frontiers of Environmental Science and Engineering in China 4(1), 102-107.

Water Pollution Control Federation. 1985 WPCF Wastewater Treatment, Sludge Conditioning, Thickening and Dewatering. WPCF, Washington D.C.

Yen,P. S., Chen, L., Chien, C., Wu, R. M. \& Lee,D. 2002 Network strength and dewaterability of flocculated activated sludge. Water Research 36(3), 539-550.

Yin, X., Han, P., Lu, X. \& Wang, Y. 2004 A review on the dewaterability of bio-sludge and ultrasound pretreatment. Ultrasonics Sonochemistry 11(6), 337-348.

Yu, G. H., He, P. J., Shao, L. M. \& He, P. P. 2008 Stratification structure of sludge flocs with implications to dewaterability. Environmental Science and Technology 42(21), 79447949. 